\title{
Out of the silos: embedding injury prevention into the Sustainable Development Goals
}

\author{
Tracey Ma (D) , 1,2 Amy E Peden (D) , 1,2 Margaret Peden (D) , 1,3 Adnan A Hyder, ${ }^{4}$ \\ Jagnoor Jagnoor (D) , ${ }^{2}$ Leilei Duan, ${ }^{5}$ Julie Brown, ${ }^{2,6}$ Jonathon Passmore, ${ }^{7}$ \\ Kathleen Clapham (10) , Maoyi Tian, ${ }^{2,9}$ A K M Fazlur Rahman, ${ }^{10,11}$ \\ Rebecca Q Ivers \\ 1,2
}

For numbered affiliations see end of article.

\section{Correspondence to}

Professor Rebecca Q Ivers, School of Population Health, University of New South Wales, Sydney, New South Wales, Australia; rebecca.ivers@unsw. edu.au

Received 26 May 2020 Revised 9 August 2020 Accepted 14 August 2020 Published Online First 11 September 2020

\section{Check for updates}

(C) Author(s) (or their employer(s)) 2021. No commercial re-use. See rights and permissions. Published by BMJ.

To cite: $M a T$, Peden $A E$ Peden $\mathrm{M}$, et al. Inj Prev 2021:27:166-171.

\begin{abstract}
Globally, unintentional injuries contribute significantly to disability and death. Prevention efforts have traditionally focused on individual injury mechanisms and their specific risk factors, which has resulted in slow progress in reducing the burden. The Sustainable Development Goals (SDGs) represent a global agenda for promoting human prosperity while respecting planetary boundaries. While injury prevention is currently only recognised in the SDG agenda via two road safety targets, the relevance of the SDGs for injury prevention is much broader. In this State of the Art Review, we illustrate how unintentional injury prevention efforts can be advanced substantially within a broad range of SDG goals and advocate for the integration of safety considerations across all sectors and stakeholders. This review uncovers injury prevention opportunities within broader global priorities such as urbanisation, population shifts, water safeguarding and corporate social responsibility. We demonstrate the relevance of injury prevention efforts to the SDG agenda beyond the health goal (SDG 3) and the two specific road safety targets (SDG 3.6 and SDG 11.2), highlighting 13 additional SDGs of relevance. We argue that all involved in injury prevention are at a critical juncture where we can continue with the status quo and expect to see more of the same, or mobilise the global community in an 'Injury Prevention in All Policies' approach.
\end{abstract}

\section{INTRODUCTION}

The Sustainable Development Goals (SDGs) are the blueprint to achieve a better and more sustainable future for all. The SDGs address global challenges such as poverty, inequality, climate change, environmental degradation, peace and justice. ${ }^{1}$ They were developed in 2012 as a follow-up to the Millennium Development Goals (MDGs) after their 2015 deadline. The 17 SDGs, 169 targets and 232 indicators were ratified by all UN Member States and adopted in 2015, with sights set on their achievement by 2030. Notably, the SDGs are designed to be "integrated and indivisible, global in nature and universally applicable" so that no one is left behind. ${ }^{2}$ Such integration has far-reaching implications. It suggests that progress cannot be achieved without all goals being met and compels a far broader range of stakeholders to apply their resources to the largest extent possible towards this global agenda.
From an injury prevention standpoint, the SDGs offer an unprecedented opportunity to integrate safety considerations across all sectors and stakeholders; and to pursue safety within all societal endeavours, whether vocational, social or recreational activities. Injuries-bodily damages that result from acute exposure to energy or from a lack of vital elements such as oxygen - are a leading cause of mortality and morbidity. Globally, in 2017, there was an estimated 321 million new cases of unintentional injury resulting from road traffic; falls; drowning; exposure to fire, heat and hot substances; poisoning; and exposure to mechanical forces. ${ }^{3}$ This contributed to a total non-fatal health loss of $\sim 41$ million years lived with disability (YLD). ${ }^{3}$

\section{Slow pace of progress in preventing unintentional injuries}

Over time, the combined burden of unintentional injuries associated with the aforementioned injury mechanisms has continued to increase. Specifically, between 2007 and 2017, the age-standardised rates of YLD have risen by $\sim 22 \%$. $^{3}$ For road traffic injuries (RTIs), which have received greater attention in the SDG agenda, current achievements will not be enough. Projections show that, based on the current pace of progress, there is a less than $5 \%$ probability that the SDG target (SDG 3.6) of halving road traffic mortality will be attained. ${ }^{4}$ This lack of substantial progress also means that the significant economic impact of injuries will continue to occur. RTIs, for example, are estimated to cost the global economy \$1.8 trillion US 2010 dollars between 2015 and $2030 .^{5}$ On a country level, it is estimated that countries who do not invest in road safety could miss out on between $7 \%$ and $22 \%$ in potential per capita gross domestic product growth. ${ }^{6}$ These numbers paint a dire picture and speak to the need for injury prevention efforts to be expanded.

\section{Persisting inequitable burden of unintentional injuries}

Expanding our collective efforts to prevent injuries is also vital to promoting health equity, as the impact of injuries on morbidity and mortality is far from even. This inequity is apparent across multiple sections of society, including by age, sex, ethnicity and region, and for multiple causes of injury. For example, among children under the age of 15 , the 


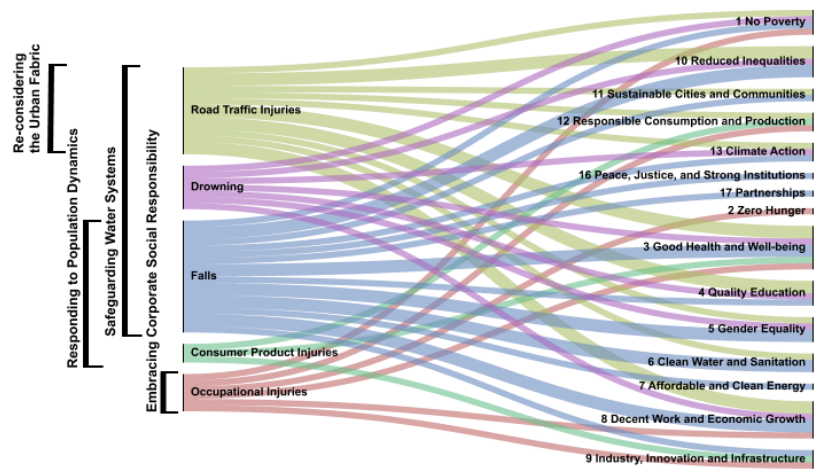

Figure 1 Linkages between global priorities, injury mechanisms and the relevant Sustainable Development Goals.

disability-adjusted life years (DALY) rate for all injury is lowest in western Europe and highest in central sub-Saharan Africaan approximately 14 -fold difference among boys and 16-fold difference among girls. ${ }^{7}$ Among adults aged 15 to 49 years, the DALY rate varies between 2651 per 100000 population to 10 780 per 100000 population for men and 798 per 100000 population to 3268 per 100000 population for women, depending on the region of the world. ${ }^{7}$ The inequitable burden of injury persists among the 50-79 years of age cohort and the 80 and over cohort, varying by region of the world.

Importantly, inequities in injury burden are not only present at the macro (between-country) level. Rather, they are evident at the national and sub-national level and between individuals. A review of global research on children's unintentional injuries and socioeconomic (SES) inequality concluded that low SES is often greatly detrimental to child safety. ${ }^{8}$ Another review of global research on children's unintentional injuries found that Indigenous children experience a significantly higher burden of morbidity and mortality from unintentional injuries across different Indigenous communities worldwide. ${ }^{9}$ Both sets of findings reinforce the theory of social conditions as fundamental causes of poor health states. ${ }^{10}$ The latter finding, specifically, draws attention to the socio-historical and socio-political circumstances surrounding Indigenous peoples, who have experienced colonisation and dispossession of lands, who often remain marginalised with less access to appropriate services and who experience higher rates of injury as a result. ${ }^{11}$ The fact that stark inequities exist, and persist, ${ }^{12}$ in injury burden reinforces the global imperative to advance injury prevention efforts in new and unprecedented ways.

\section{Expanding injury prevention efforts to align with the SDGs}

Currently, injury prevention is included in the SDG agenda via two road safety targets-SDG 3.6 and SDG 11.2. These targets are complemented by 12 voluntary global performance targets and 36 corresponding indicators, which are based on a safe system approach and focus on road safety management, safer roads and mobility, safe vehicles, safe road users and post-crash response. ${ }^{13}$ Despite this limited attention on injury prevention of the SDG agenda, injury prevention efforts can be advanced substantially within a broad range of SDG goals.

Expanded efforts require a shift away from current ways of thinking and working, which tend to focus on individual injury mechanisms and their specific risk factors, necessitating a move towards a new paradigm that recognises and embraces global priorities. By positioning injury prevention efforts within broader global priorities, the global community can make stronger advances towards SDG achievement while simultaneously reducing injury-related harm. This State of the Art Review uncovers injury prevention opportunities within the contexts of urbanisation, population shifts, water safeguarding and corporate social responsibility. We demonstrate the relevance of injury prevention efforts to the SDG agenda beyond the health goal (SDG 3) and the two specific road safety targets (SDG 3.6 and SDG 11.2).

\section{CRITICAL ISSUES}

In this section, we discuss several key global priorities and the injury prevention opportunities within these, as seen through the lens of the SDGs (see figure 1). Expanding beyond our injury prevention silos is vital to capitalise on the global momentum behind the SDGs and to see real change in injury-related mortality and morbidity. The importance of maximising synergies has been previously shown to be critical to achievement of the SDG agenda. ${ }^{14} 15$

\section{Re-considering the urban fabric}

Urbanisation is a transformative change occurring across the globe. More than half of the world's population already reside in urban areas. ${ }^{16}$ Between 2018 and 2030, the urban population is expected to increase from 4.2 billion to 5.2 billion. ${ }^{16}$ As urbanisation continues, there is increasing pressure to successfully manage cities to maximise the benefits of agglomeration while minimising environmental degradation and other negative effects. ${ }^{16}$ This intent is largely captured in SDG 11, to make cities and human settlements inclusive, safe, resilient and sustainable. Land use planning and urban design are key activities in this process, and are often directed towards promoting liveability, economic productivity and environmental sustainability. As land use planning and urban design decisions determine the quantity and quality of transportation infrastructure, they also have a function in RTI prevention. Specifically, they have the potential to influence, at scale, behaviours such as safe driving practices and modal choices.

Speed control is one of the most effective strategies for preventing RTIs, as each 5\% increase in mean speed leads to a $20 \%$ increase in fatal collisions. ${ }^{17}$ Estimates indicate that significant numbers of lives could be saved and DALYs averted from speed control, ${ }^{18}$ especially in low-income and middle-income countries, where the burden of RTIs is especially pronounced. ${ }^{19}$ Speed control can be effectively achieved through environmental designs that make it difficult to travel at high speeds. For example, small-scale environmental designs such as areawide traffic calming schemes have been demonstrated to reduce the number of injurious collisions. ${ }^{20}$ Furthermore, emerging evidence suggests that such lower speed zones have positive impacts on range of public health outcomes (SDG 3). ${ }^{21}$ In addition to their role in promoting road safety and public health, lower speeds facilitate a mixed-traffic environment that accommodates all road users, particularly those who use nonmotorised modes of transport, who are often neglected in the roadway design in many countries. ${ }^{19}$ This, therefore, enhances the inclusiveness of environments (SDG 11.7), enabling a larger proportion of the population to access education (SDG 4), work (SDG 8) and basic services (SDG 1.4) in low-cost ways that mitigate transport-related social exclusion ${ }^{22}$ and therefore reduces social inequalities (SDG 10).

Population-wide shifts from private motor vehicles to other modes such as active or public transport are positive 
developments for road safety. Such large-scale modal shifts decrease collisions by reducing overall traffic volumes and increasing road safety awareness among remaining motorists. ${ }^{23}$ Moreover, uptake of non-motorised transport such as walking and cycling promotes healthy lives (SDG 3) through physical activity, which protects against non-communicable diseases (SDG 3.4). ${ }^{24}$ Enabling urban design for walking and cycling also help to mitigate the spread of infectious diseases, unlike shared modes of transport. When substituted for motorised trips, nonmotorised transport helps reduce the environmental impact of cities (SDG 11.6). Mass motorisation imposes stressors on the environment that result in air pollution, greenhouse gas emissions, noise pollution, rising urban temperatures and dwindling green space. ${ }^{24}$ Reducing these environmental stressors by decreasing car dependency and encouraging more responsible consumption and production patterns (SDG 12) advances efforts to combat climate change (SDG 13) and reduce air pollution (SDG 3.9).

The SDG agenda presents an opportunity to tackle our society's road safety challenge more systemically-to re-consider the entire urban fabric within which roadways and public spaces are a part in the context of a larger mission to promote sustainable cities and communities. ${ }^{25}$ Recent evidence suggests a potentially large role for land use planning and urban design in preventing RTIs. One such study classified 1692 cities, capturing one-third of the world's population, into 9 urban design types based on the proportion of land area dedicated to road and rail networks and estimated their burden of RTIs. ${ }^{26}$ The analysis estimated a loss of 8.71 million DALYs per year from RTIs attributable to suboptimal urban design. ${ }^{26}$ While existing urban systems are often regarded as having path-dependent and lock-in tendencies, leading to a continuation of the status quo, re-structuring cities to meet the SDGs is achievable in practice, as demonstrated by ongoing intervention studies to retrofit urban areas for modal shifts. $^{27}$

\section{Responding to population dynamics}

Population dynamics, such as changes in population growth rates, age structures and distributions of people, are closely linked to national and global developmental challenges and their solutions. ${ }^{28}$ Changes in population place pressure on many aspects of society including economies, health services and the environment. While demographic changes in past decades have led to the largest generation of youth in the world today, ${ }^{28}$ globally the population is also ageing quicker than ever before, with those aged 60 and over to comprise approximately $25 \%$ of the global population by $2050 .{ }^{29}$

The increase in the child population combined with improvements in development has resulted in changes in the childhood experience. With global development, technological innovations and greater disposable income, product-related injury trends among children have also changed. With respect to child drowning, the rise in affordable fibreglass shells led to a proliferation of in-ground backyard pools in Australia causing child drowning rates to rapidly increase ${ }^{30}$ until legislation was introduced mandating barriers between house and pool and an enforcement regime was undertaken. ${ }^{31}$ Similarly, in recent decades, mass-produced portable swimming pools have presented an even more cost-effective option, resulting in increased drowning risk among low socioeconomic households, exacerbated by ineffective enforcement of variable legislative requirements for fencing which differ at the state and territory level. ${ }^{32}$ While such legislative interventions have shown to be effective, regulatory silos can prevent best practices from being applied to all communities.

Injury prevention efforts at a systems level have also targeted child product safety through regulation, product recalls, safety labelling and consumer awareness. ${ }^{33}$ Examples such as button battery safety and poisoning reduction highlight the strength of combining action from policy-makers, advocates, researchers and industry. ${ }^{34}$ Such injury prevention measures are afforded opportunities within and clearly link to responsible consumption and production (SDG 12), good health and well-being (SDG 3), and industry, innovation and infrastructure (SDG 9).

On the other end of the lifespan, an ageing population has resulted in a greater appreciation of the need to optimise communities so that they are physically accessible and socially inclusive for older people This is the heart of the age-friendly cities approach ${ }^{35}$ which encourages local governments to design and adapt policies, systems, services, products and technologies to support older people. Importantly, the age-friendly cities approach offers an umbrella framework for embedding injury prevention efforts directed at older people within an integrated action plan at the system level. For example, age-friendly initiatives that modify the physical environment have the potential to prevent injuries from falls. Falls are a hidden contributor to pedestrian injury in that pedestrian falls are underreported ${ }^{36}$ and that pedestrian falls are more often implicated in pedestrian injuries than are pedestrian-vehicle interactions. ${ }^{37}$ The majority of pedestrian falls occur in densely populated areas ${ }^{38}$ and are associated with specific characteristics of the built environment, such as poor pavement conditions. ${ }^{37}$ In fact, estimates suggest that three-quarters or more of pedestrian falls were precipitated by environmental factors. ${ }^{39}$ The burden of falls is highest among older people ${ }^{40}$ and pedestrian falls are expected to increase as the population ages. ${ }^{39}$ Agefriendly initiatives that modify the physical environment not only contribute to preventing injuries from falls. By minimising hazards, ensuring adequate infrastructure and improving street connectivity, such initiatives also enable older people to navigate the city and access goods, services, and opportunities for social interaction and participation. Recognising these co-occurring benefits, The Stakeholder Group on Ageing asserts that age-friendly cities approaches are central to SDG 11 and contribute to SDGs 1, 3, 5. 6, 7, 8, 9, 10, 1316 and $17 .{ }^{41}$ Likewise, in upholding the value of social inclusion, scholars have advocated for extending the agefriendly cities approach to one that promotes environments for all ages and prioritises intergenerational space. ${ }^{42}$ The consideration of communities from a life course and intergenerational approach has also resulted in specific child-friendly initiatives such as the Streets for Kids programme. ${ }^{43}$

\section{Safeguarding water systems}

Two-thirds of the world's population experience severe water scarcity at least 1 month a year. ${ }^{44}$ Over 1.8 billion people do not have reliable access to safe drinking water, ${ }^{45}$ the lack of which leads to health risks from microbial contamination ${ }^{45}$ and contributes to the burden of diarrheal deaths. ${ }^{46}$ In addition, the lack of access to running water and soap undermines infection control efforts. Ensuring communities have reliable access to clean water and sanitation is the focus of the WASH targets ${ }^{46}$ and of SDG 6, which aims to ensure availability and sustainable management of water and sanitation for all. Safeguarding water systems is also important from an injury prevention perspective, as daily contact with water for work, transport, agriculture and nourishment is implicated in injury risk from motor traffic collisions, falls and drowning. 
Water insecurity is predominantly concentrated in low-income and middle-income countries, where water sources tend to be located outside the home and water fetching is a recurring daily task. Women and children are the most common water carriers, and they incur high costs associated with water carrying including time spent, caloric expenditure, and the opportunity cost of engaging in education (SDG 4) or income-generating activities (SDG 8). ${ }^{47}$ In addition, water carrying, necessitated by out-ofhome drinking water infrastructure, often involves walking on poorly designed roadways shared with vehicles, increasing the risk of traffic injury, and uneven terrains or slippery landscapes, leading to falls and slips (SDG 3). ${ }^{48}$ A recent systematic review draws attention to these injury risks, which involve exposure from water fetching to dangerous animals, open bodies of water, floods and motor vehicles. ${ }^{49}$ Another review highlighted the association between water fetching and musculoskeletal disease burden, including pain in the hands, back and spinal regions. ${ }^{50}$

Population growth, urbanisation and weather fluctuations exacerbate the negative effects of water insecurity, and women and those in poor regions of the world are expected to bear the brunt of it, ${ }^{47}$ undermining the goals of gender equality (SDG 5 ) and reducing inequalities (SDG 10). Furthermore, increased global temperatures due to climate change lead to increased evaporation of surface water which may also threaten water supply. ${ }^{51}$ While water insecurity relates to inadequate or insufficient access to water, particularly for drinking purposes, a related water management issue is the excessive or repeated access to it in the form of open bodies of water. Drowning is one of the leading causes of death in children, and drowning incidences predominantly occur in low-income and middle-income countries where infrastructure, such as those that manage flood risks and create barriers to open bodies of water, are underdeveloped. ${ }^{52}$ In such countries, economic growth is often an effective lever for improving health and protecting lives, as health and wealth are mutually reinforcing ${ }^{53}$ and as economic resources improve the capacity to invest in preventive infrastructure.

Efforts to increase economic productivity may have simultaneous co-benefits, including preventing injuries (SDG 3). Anchals (otherwise known as crèches or nurseries) are a form of community supervision for children ages 1 to 5 provided during the hours in which parents worked. They facilitate parents to work (SDG 8), contributing to household poverty reduction (SDG 1), by providing safe childcare arrangements and early education opportunities (SDG 4). They also engage local women in staffing the anchal and supervising children which promotes their opportunities to contribute to society in line with SDG 5, which focuses on gender equality. From an injury prevention standpoint, anchals ensure that children are not left unsupervised, especially around bodies of water. In Bangladesh, drowning accounts for $43 \%$ of deaths among children age 1 and 4 , the majority of which occurred in natural bodies of water, close to where households are located, during daylight hours when the child was alone or with other children. ${ }^{54}$ When implemented in rural Bangladesh, anchals were found to be both effective and cost-effective in preventing childhood drowning. ${ }^{54}$

Managing water systems in regard to shortfalls in supply and to uncontrolled access to open bodies of water is a global challenge with implications for injury burden. Similarly, mitigation strategies against the effects of climate change (SDG 13), such as sea level rises and extreme weather events like storm surge flooding, contribute towards decreasing the risk of drowning for vast segments of the global population. ${ }^{51}$ This is particularly important from the perspective of reducing inequalities (SDG 10) and building the resilience of those in vulnerable situations
(SDG 1.5), as flood-related deaths, which occur acutely from drowning or trauma (being hit by objects in fast-flowing waters), are highest in places where infrastructure is poor and the population at risk has limited economic resources. ${ }^{55}$

\section{Embracing corporate social responsibility}

The emphasis on economic productivity places increasing demands on workers, who may be at risk to injuries related to work or through their occupation. At its worse, this may lead to a prioritisation of output over human welfare. A high-profile example are injuries sustained in factory collapses by garment workers as a result of a prioritisation of production over worker's physical and environmental safety. ${ }^{56}$ The 2013 collapse of the Dhaka garment factory Rana Plaza was the deadliest disaster in the garment industry, resulting in the deaths of more than 1100 workers. ${ }^{57}$ It drew worldwide attention to parts of the global supply chain and raised the issue of improving working conditions for lower-wage workers in developing countries. ${ }^{57}$ The tragedy prompted pushback against 'fast fashion' with a move towards more ethical clothing purchasing. At a policy level, the Dhaka factory collapse resulted in changes to Bangladesh's labour laws including making it easier to join a labour union. The Bangladesh government also introduced plans to complete comprehensive safety assessments of all export-oriented garment factories. ${ }^{57}$ These policy responses help to prevent injury occurrence within the context of the garment manufacturing sector, which is key to the country's economic growth (SDG 8) and to household poverty reduction (SDG 1 ). This example again demonstrates the potential for advancing injury prevention efforts at the systems level, in harmony with a range of SDG goals.

Additional examples can be found in other sectors, such as the trucking industry, which is highly sensitive to cycles of economic expansion and contraction. With the trucking industry being an essential component of supply chains and operators being under pressure to deliver, commercial vehicle drivers face long hours on the road with comparatively little rest between shifts, making them susceptible to driving while fatigued and increasing the risk of collision for them and other road users. At the operator level, safety management practices have considerable potential to offset fatigue-inducing factors associated with truck driving work. ${ }^{58}$ At the national policy level, the UN Member States have established a target for countries to enact new, or accede to existing, regulation for driving time and rest periods for professional drivers. ${ }^{13}$ Other systems-level interventions have been put forth. For example, in Australia, the Heavy Vehicle National Law was amended in 2018 to include Chain of Responsibility rules so that every party in the heavy vehicle transport supply chain has a duty to ensure the safety of their transport activities. ${ }^{59}$ In addition, the Academic Expert Group for the third Global Ministerial Conference on Road Safety recommended the private sector embrace the road safety challenge through sustainable practices and reporting (SDG 12.6) as well as procurement (SDG 12.7). ${ }^{60}$

Promoting safety in the workplace will impact productivity and performance, while also reducing the extent of occupational injuries (SDG 3), which in 2017 accounted for 21.1 million DALYs. ${ }^{61}$ With a move towards corporate social responsibility, organisations must put the welfare of people and planet before profit. Organisations cannot be sustainable without protecting the safety, health and welfare of their most vital resource: their workers. ${ }^{62}$ The SDGs provide numerous opportunities to reduce the impact of occupational related injuries, for example, through efforts towards sustainable food production systems and 
agricultural practices (SDG 2.4), resilient infrastructure (SDG 9) and sustainable production patterns (SDG 12).

\section{CONCLUSIONS}

Public safety concerns need to be a higher priority for economic, social and political development. The SDGs provide an unprecedented opportunity for researchers, practitioners, advocates and policy-makers to embed and align injury prevention efforts within broader development agendas, ensuring that no one is left behind. The impact of this is bi-directional, as achievement of the SDGs cannot occur without reducing injury, while reducing injury will assist in realising the SDGs. Preventing mortality and morbidity due to injury is an issue that, like the SDGs themselves, is global in nature and universally applicable to high-income and low-income and middle-income contexts alike. Unlike the missed opportunity of the MDGs, the injury prevention community cannot risk allowing another opportunity to mobilise the global community in a 'health in all policies' approach to pass us by. Until there is substantial reduction in injury mortality and morbidity, the SDGs will not be achieved.

\author{
Author affiliations \\ ${ }^{1}$ School of Population Health, University of New South Wales, Sydney, New South \\ Wales, Australia \\ ${ }^{2}$ The George Institute for Global Health, University of New South Wales, Sydney, New \\ South Wales, Australia \\ ${ }^{3}$ The George Institute for Global Health, Imperial College London, London, UK \\ ${ }^{4}$ Milken Institute School of Public Health, George Washington University, \\ Washington, DC, USA \\ ${ }^{5}$ National Center for Chronic and Noncommunicable Disease Control and Prevention, \\ Chinese Center for Disease Control and Prevention, Beijing, China \\ ${ }^{6}$ Neuroscience Research Australia, Sydney, New South Wales, Australia \\ ${ }^{7}$ World Health Organization Regional Office for Europe, Copenhagen, Denmark \\ ${ }^{8}$ Ngarruwan Ngadju First Peoples Health and Wellbeing Research Centre, Australian \\ Health Services Research Institute, University of Wollongong, Wollongong, New \\ South Wales, Australia \\ ${ }^{9}$ The George Institute for Global Health, Peking University Health Science Center, \\ Beijing, China \\ ${ }^{10}$ The Centre for Injury Prevention and Research, Bangladesh, Dhaka, Bangladesh \\ ${ }^{11}$ Bangladesh University of Health Sciences, Dhaka, Bangladesh
}

Contributors RQI conceptualised this study. TM, AEP and RQI drafted the study. TM created the data visualisation. MP, AAH, JJ, LD, JB, JP, KC, MT and AKMFR provided critical revision of the manuscript. All authors approved the submitted version.

Funding The authors have not declared a specific grant for this research from any funding agency in the public, commercial or not-for-profit sectors.

Competing interests None declared.

Patient and public involvement Patients and/or the public were not involved in the design, or conduct, or reporting, or dissemination plans of this research.

Patient consent for publication Not required.

Provenance and peer review Not commissioned; externally peer reviewed.

\section{ORCID iDs}

Tracey Ma http://orcid.org/0000-0003-0106-5116

Amy E Peden http://orcid.org/0000-0002-6424-1511

Margaret Peden http://orcid.org/0000-0003-0872-9851

Jagnoor Jagnoor http://orcid.org/0000-0002-5276-9095

Kathleen Clapham http://orcid.org/0000-0001-9776-5496

Rebecca Q Ivers http://orcid.org/0000-0003-3448-662X

\section{REFERENCES}

1 United Nations Sustainable Development. About the sustainable development goals. Available: https://www.un.org/sustainabledevelopment/sustainable-developmentgoals/ [Accessed 24 Jun 2020].

2 United Nations General Assembly. Transforming our world: the 2030 agenda for sustainable development, 2015.

3 James SL, Abate D, Abate KH, et al. Global, regional, and national incidence, prevalence, and years lived with disability for 354 diseases and injuries for 195 countries and territories, 1990-2017: a systematic analysis for the global burden of disease study 2017. Lancet 2018;392:1789-858.

4 Lozano R, Fullman N, Abate D, et al. Measuring progress from 1990 to 2017 and projecting attainment to 2030 of the health-related sustainable development goals for 195 countries and territories: a systematic analysis for the global burden of disease study 2017. Lancet 2018:392:2091-138.

5 Chen S, Kuhn M, Prettner K, et al. The global macroeconomic burden of road injuries: estimates and projections for 166 countries. Lancet Planet Health 2019;3:e390-8.

6 Bank W. The high toll of traffic injuries: unacceptable and preventable. Available: https://openknowledge.worldbank.org/handle/10986/29129

7 Haagsma JA, Graetz N, Bolliger I, et al. The global burden of injury: incidence, mortality, disability-adjusted life years and time trends from the global burden of disease study 2013. Inj Prev 2016;22:3-18.

8 Laflamme L, Hasselberg M, Burrows S. 20 years of research on socioeconomic inequality and children's - unintentional injuries understanding the cause-specific evidence at hand. Int J Pediatr 2010;2010. doi:10.1155/2010/819687. [Epub ahead of print: $25 \mathrm{Jul} 2010]$.

9 Möller $\mathrm{H}$, Falster $\mathrm{K}$, Ivers $\mathrm{R}$, et al. Inequalities in unintentional injuries between indigenous and non-Indigenous children: a systematic review. Inj Prev 2015;21:e144-52.

10 Link BG, Phelan J. Social conditions as fundamental causes of disease. J Health Soc Behav 1995;Spec No:80-94.

11 Berger LR. Injury prevention and indigenous peoples. Inj Prev 2002;8:175-6.

12 Sengoelge $M$, Leithaus $M, B r a u b a c h ~ M$, et al. Are there changes in inequalities in injuries? A review of evidence in the WHO European region. Int I Environ Res Public Health 2019;16. doi:10.3390/ijerph16040653. [Epub ahead of print: $22 \mathrm{Feb}$ 2019].

13 WHO. Developing global targets for road safety risk factors and service delivery mechanisms. Available: http://www.who.int/violence_injury_prevention/road_trafficl road-safety-targets/en/ [Accessed 8 Feb 2020].

14 Kroll C, Warchold A, Pradhan P, et al. Sustainable development goals (SDGs): are we successful in turning trade-offs into synergies? Palgrave Commun 2019;5.

15 Pradhan P, Costa L, Rybski D, et al. A systematic study of sustainable development goal (SDG) interactions. Earths Future 2017;5:1169-79.

16 United Nations Department of Economic and Social Affairs. World urbanization prospects: 2018 revision. Available: https://population.un.org/wup/Publications/ [Accessed 28 Apr 2019].

17 IRTAD. "Speed management," Organization for Economic Cooperation and Development and European Conference of Ministers of Transport, Paris, France, 2006. Available: https://www.itf-oecd.org/sites/default/files/docs/06speed.pdf

18 Bhalla K, Mohan D, O'Neill B, O'Neill B. How much would low- and middle-income countries benefit from addressing the key risk factors of road traffic injuries? Int I Inj Contr Saf Promot 2020;27:83-90.

19 World Health Organization. Global status report on road safety. Geneva, 2018.

20 Elvik R. Area-wide urban traffic calming schemes: a meta-analysis of safety effects. Accid Anal Prev 2001;33:327-36.

21 Cleland CLet al. Effects of 20 mph interventions on a range of public health outcomes: a meta-narrative evidence synthesis. J Transp Health 2019.

22 Lucas K. Transport and social exclusion: where are we now? Transp Policy 2012;20:105-13.

23 Elvik R, Bjørnskau T. Safety-in-numbers: a systematic review and meta-analysis of evidence. Saf Sci 2017;92:274-82.

24 Khreis H, Warsow KM, Verlinghieri E, et al. The health impacts of traffic-related exposures in urban areas: understanding real effects, underlying driving forces and co-producing future directions. J Transp Health 2016;3:249-67.

25 Akuraju V, Pradhan P, Haase D, et al. Relating SDG11 indicators and urban scaling an exploratory study. Sustain Cities Soc 2020;52:101853.

26 Thompson J, Stevenson M, Wijnands JS, et al. A global analysis of urban design types and road transport injury: an image processing study. Lancet Planet Health 2020;4:e32-42.

27 Macmillan A, Smith M, Witten K, et al. Suburb-level changes for active transport to meet the SDGs: causal theory and a New Zealand case study. Sci Total Environ 2020;714, :136678.

28 UNDESA, UNFPA. UN system task team on the post-2015 UN development agenda: population dynamics thematic think piece, 2012. Available: https://www.un.org/ millenniumgoals/pdf/Think\%20Pieces/15_population_dynamics.pdf.

29 United Nations Department of Economic and Social Affairs. World population prospects: the 2017 revision. Key findings and advance tables. New York, 2017.

30 Pearn J, Nixon J, Wilkey I, et al. Freshwater drowning and near-drowning accidents involving children: a five-year total population study. Med J Aust 1976;2:942-6.

31 Franklin RC, Peden AE. Improving pool fencing legislation in Queensland, Australia: attitudes and impact on child drowning fatalities. Int I Environ Res Public Health 2017;14. doi:10.3390/ijerph14121450. [Epub ahead of print: 24 Nov 2017].

32 Peden AE, Franklin RC, Pearn JH. The prevention of child drowning: the causal factors and social determinants impacting fatalities in portable pools. Health Promot J Austr 2020;31:184-91. 
33 Niven CM, Mathews B, Harrison JE, et al. Hazardous children's products on the Australian and US market 2011-2017: an empirical analysis of child-related product safety recalls. Inj Prev 2020;26:344-350.

34 Jatana KR, Chao S, Jacobs IN, et al. Button battery safety: industry and academic partnerships to drive change. Otolaryngo/ Clin North Am 2019;52:149-61.

35 World Health Organization. Global age-friendly cities: a guide, 2007. Available: http:// www.who.int/ageing/publications/age_friendly_cities_guide/en/ [Accessed 15 Feb 2019].

36 Oxley J, O'Hern S, Burtt D, et al. Falling while walking: a hidden contributor to pedestrian injury. Accid Anal Prev 2018;114:77-82.

37 Methorst R, Schepers P, Christie N, et al. 'Pedestrian falls' as necessary addition to the current definition of traffic crashes for improved public health policies. J Transp Health 2017:6:10-12.

38 Ceccato V, Willems 0 . Temporal and spatial dynamics of falls among older pedestrians in Sweden. App/ Geogr 2019;103:122-33.

39 Schepers $P$, den Brinker $B$, Methorst $R$, et al. Pedestrian falls: a review of the literature and future research directions. J Safety Res 2017;62:227-34.

40 James SL, Lucchesi LR, Bisignano C, et al. The global burden of falls: global, regional and national estimates of morbidity and mortality from the global burden of disease study 2017. Inj Prev 2020;26:i3-11.

41 Stakeholder Group on Ageing. Position paper submitted to the High-Level Political Forum 2018. Goal 11: building inclusive, safe, resilient and sustainable cities for al ages, including older persons. Available: https://sustainabledevelopment.un.org/ content/documents/18825StakeholderGroup_on_Ageing_Sectoral_Paper_2018HLPF. pdf

42 Biggs S, Carr A. Age- and child-friendly cities and the promise of intergenerational space. J Soc Work Pract 2015;29:99-112.

43 National Association of City Transportation Officials. Streets for Kids, 2019. Available: https://nacto.org/program/streets-for-kids [Accessed 18 May 2020].

44 Mekonnen MM, Hoekstra AY. Four billion people facing severe water scarcity. Sci Adv 2016;2, :e1500323.

45 Onda K, LoBuglio J, Bartram J. Global access to safe water: accounting for water quality and the resulting impact on MDG progress. Int J Environ Res Public Health 2012;9:880-94.

46 World Health Organization. Preventing diarrhoea through better water, sanitation and hygiene: exposures and impacts in low- and middle-income countries, 2014. Available: https://www.who.int/water_sanitation_health/publications/gbd_poor_ water/en/

47 Sorenson SB, Morssink C, Campos PA. Safe access to safe water in low income countries: water fetching in current times. Soc Sci Med 2011;72:1522-6.
48 Adams EA, Stoler J, Adams Y. Water insecurity and urban poverty in the Global South: implications for health and human biology. Am J Hum Biol 2020;32, :e23368.

49 Geere J-AL, Cortobius M, Geere JH, et al. Is water carriage associated with the water carrier's health? A systematic review of quantitative and qualitative evidence. BMJ Glob Health 2018;3:e000764.

50 Geere J-A, Bartram J, Bates L, et al. Carrying water may be a major contributor to disability from musculoskeletal disorders in low income countries: a cross-sectional survey in South Africa, Ghana and Vietnam. J Glob Health 2018;8, :010406.

51 Roberts I, Hillman M. Climate change: the implications for policy on injury control and health promotion. Inj Prev 2005;11:326-9.

52 The Lancet. Drowning: a silent killer. Lancet 2017:389:1859.

53 Figueras J, McKee M. Health systems, health, wealth and societal well-being: assessing the case for investing in health systems. Milton Keynes, United Kingdom: Open University Press, 2012

54 Rahman F, Bose S, Linnan M, et al. Cost-effectiveness of an injury and drowning prevention program in Bangladesh. Pediatrics 2012;130:e1621-8.

55 Ahern M, Kovats RS, Wilkinson P, et al. Global health impacts of floods: epidemiologic evidence. Epidemiol Rev 2005;27:36-46.

56 Taplin IM. Who is to blame?: a re-examination of fast fashion after the 2013 factory disaster in Bangladesh. Crit Perspect Int Bus; 10.

57 Bolle MJ. Bangladesh apparel factory collapse: background in brief. Congressiona research service 7-5700. Available: https://fas.org/sgp/crs/row/R43085.pdf

58 Morrow PC, Crum MR. Antecedents of fatigue, close calls, and crashes among commercial motor-vehicle drivers. J Safety Res 2004;35:59-69.

59 National Heavy Vehicle Regulator. About chain of responsibility. Available: https:// www.nhvr.gov.au/safety-accreditation-compliance/chain-of-responsibility/about [Accessed 8 Apr 2020].

60 Swedish Transport Administration. Saving lives beyond 2020: the next steps. Recommendations of the academic expert group for the 3rd Global Ministerial Conference on Road Safety, 2020. Available: https://www.roadsafetysweden.com/ contentassets/c65bb9192abb44d5b26b633e70e0be2c/200113_final-report-single. pdf

61 GBD 2017 Risk Factor Collaborators. Global, regional, and national comparative risk assessment of 84 behavioural, environmental and occupational, and metabolic risks or clusters of risks for 195 countries and territories, 1990-2017: a systematic analysis for the global burden of disease study 2017. Lancet 2018;392:1923-94.

62 Lamm F, Massey C, Perry M. Is there a link between workplace health and safety and firm performance and productivity? N Z J Employ Relat 2006;32:75. 